\title{
Conocimiento de la realidad y transformación social
}

\section{Miguel Beltrán Villalva}

Universidad Autónoma de Madrid. Departamento de Sociología

miguel.beltran@uam.es

Recibido: 05-07-2010

Aceptado: 21-06-2011

\section{Resumen}

El papel del sociólogo en tanto que científico social consiste en desarrollar el conocimiento objetivo de la realidad, lo que implica una labor emancipatoria al negar el discurso de los idola. Pero puede ir más allá, asesorando a los centros políticos de decisión con la aportación de un principio de realidad y con la crítica técnica de los valores. Pero no puede asumir la responsabilidad de adoptar decisiones políticas tecnocráticas en nombre de la autoridad de la ciencia.

Palabras clave: asesoramiento; ciencia; crítica técnica; emancipación; principio de realidad; reflexividad; tecnocracia; valores.

\section{Abstract. Knowledge of reality and social change}

The role of the sociologist qua social scientist is to develop an objective knowledge of reality. That entails emancipatory work in order to deny the discourse of idola. But sociologists can go further, advising political decision-making centres with a reality principle and a technical criticism of values. However, sociologists cannot assume the responsibility of making technocratic, political decisions in the name of the authority of science.

Keywords: advice; science; technical criticism; emancipation; reality principle; reflexivity; technocracy; values.

\section{Sumario}

sociedad $\rightarrow$ conocimiento $\rightarrow$ sociedad

2. Episteme y phrónesis

3. La cesura entre ser y deber ser y la normatividad de la ciencia

4. Para un tratamiento crítico-racional de los fines sociales
5. La reflexividad transformadora

6. Asesoría a los centros de decisión

7. Para concluir

Referencias bibliográficas 


\section{Introducción: sociedad $\rightarrow$ conocimiento $\rightarrow$ sociedad}

En las páginas que siguen, planteo uno de los problemas básicos de las ciencias sociales que, a mi entender, carece de una solución clara y satisfactoria. No es la primera vez que intento avanzar en este tejer y destejer, aunque he de reconocer que sin mucho éxito. Creo, no obstante, que, por muy fatigados que estén ciertos problemas, hay que volver sobre ellos una y otra vez. Lo que insisto en indagar hoy tiene que ver con la utilización del conocimiento obtenido por las ciencias sociales para la transformación de la realidad social, o, si se prefiere, trato de explorar la eventual condición normativa de la sociología (una cuestión relativa a la praxis). Ello tiene obviamente que ver con la sociología del conocimiento, por referirse al papel que el conocimiento haya de desempeñar no sólo en la descripción y explicación de la sociedad, sino en su transformación, como quería la marxiana «tesis once» sobre Feuerbach. Podría decirse que se trata de un tema básico: la utilización, deliberada o no, de ese conocimiento para cambiar la realidad, no sólo como una suerte de sociología del conocimiento al revés, en la que el juego de la (auto)reflexividad llevaría a cambios sociales derivados del hecho de que la sociedad se contempla en el conocimiento que sobre ella logran las ciencias sociales, sino como consecuencia de la utilización de un conocimiento que no se habría logrado por amor al arte (esto es, por mera curiosidad científica), sino para conseguir una sociedad mejor, sea fijando los objetivos a que hubiere de tender, sea estableciendo los medios adecuados para alcanzarlos.

Las relaciones entre realidad social y conocimiento de la realidad social constituyen un caso sumamente peculiar de las que se dan entre mundo y ciencia, ante todo, porque la realidad social es muy compleja, mucho más que la físico-natural, pues está impregnada de sentido que configura su estructura y su funcionamiento. Y, en la misma línea, los individuos que la componen hablan, emiten mensajes complejos de los que depende su comportamiento y el de los demás; y lo hacen en una lengua (de entre una enorme variedad de ellas) que no ha creado ninguno de los hablantes, sino que todos han aprendido. Por otro lado, la realidad social es histórica, cambiante, en muchas ocasiones de manera más o menos brusca (lo que permite, por ejemplo, hablar de la revolución industrial para referirse al proceso de industrialización occidental). Es verdad que el mundo físico-natural es también un objeto histórico, cosa evidente, al menos, desde Darwin, pero se trata de una historia de onda larga, de cambios gigantescos pero que acontecen muy lentamente o, si son bruscos, muy de tarde en tarde.

El conocimiento que las ciencias sociales logran de la realidad que estudian está, inevitablemente, coloreado por los valores, los prejuicios y las ideologías del investigador, incluso desde la elección del objeto de conocimiento (cuya relevancia viene determinada, así lo piensa Weber, por los valores del estudioso). No es el caso abordar aquí un inventario de los argumentos que se han formulado para mostrar que, pese a ello, la ciencia social es posible como tal ciencia. Baste con apuntar que así se admite, gracias sobre todo al papel 
crítico que la comunidad científica desempeña. No hay que decir que esta coloración ideológica afecta también a la mirada que dirigen a la realidad físiconatural quienes la estudian, pero en dichas ciencias no se plantea el problema de manera tan aguda, quizás porque los científicos (o mejor, las comunidades científicas particulares de cada campo) son más críticos con las contribuciones de sus colegas.

El planteamiento epistemológico tradicional, de orientación positivista, se basa en la convicción de que la realidad existe independientemente de nuestra observación y del conocimiento que logremos de ella. No toda la realidad es directamente observable, pero el positivismo utiliza indicadores o mediciones indirectas cuando el caso lo requiere. Se trata, pues, de un planteamiento objetivista, para el que el conocimiento descansa en la observación, que no altera la naturaleza o el comportamiento de lo observado y que es empíricamente verificable. Pero la posición epistemológica que exige la sociología del conocimiento es muy diferente, ya que afirma que todo conocimiento viene marcado por el medio social y cultural en que se produce, que tiene sobre él una influencia inevitable. Es, pues, un conocimiento histórico y, consecuentemente, se trata de un producto social, lo que no supone que esté afectado de relativismo, aunque la verdad científica no pueda adornarse con la pretensión de ser absoluta, sino que es provisional en tanto no sea falsada; y es convencional, porque su condición de «verdad» depende de su aceptación por la comunidad científica.

Todo ello coincide con lo que la sociología del conocimiento ha señalado acerca de la ciencia: que no se produce en el vacío, sino en un contexto social (cultural, económico, político) que influye en ella, la condiciona o la determina. Piénsese, por ejemplo, en la financiación de las investigaciones, muchas de ellas sumamente costosas, en el trabajo de grupos más o menos grandes de investigadores (el viejo modelo de investigador aislado ya no es imaginable), o en el papel que desempeñan las asociaciones científicas internacionales al sugerir los campos que deben ser cubiertos. Y ello por no hablar de la ciencia como una actividad social, ciertamente peculiar, pero susceptible de ser estudiada sociológicamente como otra cualquiera. Pero no se trata sólo de que la ciencia se produzca en un contexto social determinado, sino que, como es obvio, la ciencia tiene un poderosísimo influjo sobre la sociedad. No en vano manejamos hoy habitualmente la expresión sociedad del conocimiento para referirnos a determinadas características del mundo actual. Influjo que no se limita, ni mucho menos, a la ciencia aplicada y a la omnipresencia de las tecnologías de ella derivadas, sino que se abre a fenómenos de reflexividad, en los que la sociedad se ve reflejada en el espejo que forma lo que la ciencia dice de ella, lo cual afecta no sólo al conocimiento que la sociedad va teniendo de sí misma, sino también al mismo comportamiento que tiene lugar en la acción social (siempre se recuerda, por ejemplo, que la publicación de los sondeos electorales afecta al comportamiento electoral, aunque se discuta si para el que se anuncia como ganador habrá más o menos votos, esto es, si los efectos del anuncio serán el de aumentarlos, bandwagon, o el de disminuirlos, underdog). Por su parte, Ulrich Beck habla de modernización reflexiva como "posibilidad de una (auto) 
destrucción creativa de toda una época: la de la sociedad industrial» (Beck et al., 1997: 14 y pássim).

Pues bien, una modalidad importante de este juego es la que tiene lugar cuando alguien intenta aplicar los conocimientos logrados por las ciencias sociales para transformar la realidad social: pueden encontrarse en este caso no sólo los activistas, los partidos políticos, los gobernantes o los funcionarios, sino también los propios científicos sociales, convencidos de tener la solución a un problema determinado. La sociología desenvolvería, así, una función normati$v a$, de «decir lo que hay que hacer» con un apoyo racional e indiscutible, el de la ciencia social, la cual tendría como objeto lograr un mundo más satisfactorio (al menos para quien proponga la actuación de que se trate). Aunque este planteamiento haya de rechazarse por las razones que se indican más abajo, tal rechazo no puede ser absoluto. Por mucho que la sociología sea una ciencia, y una ciencia empírica, no puede abjurar de una limitada vocación normativa, a la que ya me he referido en alguna ocasión anterior, y sobre la que volveré fugazmente enseguida. Pero, como se verá, una cosa es esa forma de vocación y otra muy diferente el que el objetivo de la sociología sea cambiar la sociedad, o mejorarla, o transformarla (o tanto da, por el contrario, consagrar lo existente). Pero será mejor entrar ya en la cuestión de manera menos apresurada.

\section{Episteme y phrónesis ${ }^{1}$}

En el libro sexto de la Ética a Nicómaco ${ }^{2}$, Aristóteles distingue entre conocimiento científico (episteme) y saber práctico o prudencia (phrónesis): «la ciencia es un juicio sobre lo universal y lo que es necesariamente», "lo científico es demostrable» (capítulo VI, $\$$ ). La prudencia es, en cambio, «una disposición racional verdadera y práctica respecto de lo que es bueno y malo para el hombre»: se trata de «una virtud» que «tiene por objeto lo que puede ser de otra manera», esto es, lo no necesario (capítulo VI, $\$$ 5). Así pues, podríamos decir que el conocimiento científico de lo dado se contrapone al saber práctico de lo que puede ser y hacerse de maneras diferentes. El saber práctico «es una cualidad propia de los administradores y de los políticos» (ibídem) y, generalizando lo que Aristóteles dice, no habrá una, sino muchas phrónesis acerca de qué es lo bueno para los ciudadanos (capítulo VI, \$7). En resumidas cuentas, el conocimiento científico de la realidad social se sitúa en un plano diferente al de los criterios que orientan la práctica de la vida deseable, por lo que la ordenación política y social no puede apoyarse en las ciencias sociales: no puedo

1. Recojo aquí de nuevo mi síntesis del planteamiento aristotélico al respecto, que figura en «Anotaciones a tres textos de Carlos Moya», en: VVAA (2007), Lo que hacen los sociólogos: Libro homenaje a Carlos Moya Valgañón, Madrid, Centro de Investigaciones Sociológicas, p. 58. Me refiero también a ello en "Sobre la necesidad de acudir a los autores clásicos de la sociología», en: Antonio Ariño (ed.) (2005), Las encrucijadas de la diversidad cultural, Madrid, CIS, p. 22.

2. Utilizo la traducción de M. Araujo y J. Marías, Madrid, Instituto de Estudios Políticos, 1949. Hay ediciones posteriores. 
argumentar que la solución que yo considero adecuada, por racional que sea, es la solución científica del problema. Sólo en el caso de la técnica viene el hacer dirigido por el saber, pues la técnica no es sino conocimiento aplicado (capítulo VI, $\$ 4$ ), mientras que «la prudencia es normativa: qué se debe hacer o no, tal es el fin que se propone» (capítulo VI, $\mathbb{\$} 10$ ): no el conocimiento, sino «la virtud hace recto el fin propuesto, y la prudencia los medios que a él conducen» (capítulo VI, $\$ 12$ ).

Pero el interés por el conocimiento científico no comporta desinterés por la sociedad. Por de pronto, el conocimiento es en sí mismo emancipatorio, ya que rechaza asumir pasivamente la configuración de la realidad. Descubrir lo que las cosas son implica poder vivir de un modo auténtico, sin estar sometidos a los dictados de la superstición y la ignorancia, al imperio de los idola. Pero que la ciencia no deba establecer los fines de la vida humana o la solución de los problemas sociales (esto es, que no deba ocupar el lugar de la política) no implica en modo alguno que la política haya de ser irracional: una cosa es que la racionalidad y la lógica estén presentes en la política, y otra muy diferente que la ciencia determine cómo deban ser las cosas. Las opciones acerca de fines y medios en la vida colectiva suponen la existencia de una posible variedad: las cosas pueden ser de esta o de la otra manera, y optar por una de ellas puede ser racional o irracional, responder a la lógica o a cualquier aberración. No estará de más insistir en ello: el que los objetivos políticos no hayan de ser fijados por la ciencia, sino que deban establecerse como opciones o alternativas fundadas en ideologías, no implica su irracionalidad, o que se definan al margen de la lógica. No hay una respuesta científica, y por tanto indiscutible, a los problemas de la convivencia: las respuestas son políticas, tan racionales y lógicas como los ciudadanos sean capaces de construirlas, pero siempre contando con que ha de haber otros ciudadanos que no las prefieran. Las opciones y las preferencias motivadas por las creencias (ideologías) y los intereses responden a un tipo de racionalidad instrumental que no es el que caracteriza a la epistemología, y conducen a proposiciones discutibles. Confundir un plano y otro es lo que llevó a Frederick W. Taylor a sostener que, a causa de la aplicación de sus análisis, no tenían sentido las discusiones acerca de con qué intensidad debería hacerse el trabajo, en cuánto tiempo y a cambio de qué salario. Negociar estas cuestiones indiscutibles sería "como si se tratase de convenir por acuerdo el lugar y el momento de la salida y la puesta del sol», dijo en cierta ocasión (apud Bell, 1960: 228).

El planteamiento aristotélico contradecía directamente el de su maestro Platón, quien, inspirándose en Sócrates, sostenía que «la virtud es conocimiento", de suerte que existe objetivamente un modelo de vida buena que puede ser materia de estudio, y que cabe identificar y definir mediante procesos intelectuales adecuados: la lógica y la investigación racional. La adquisición y la aplicación de tal conocimiento por los gobernantes es la única salvación de los estados, por lo que hay quien piensa que la fundación de la Academia platónica tuvo la finalidad de inculcarlo como fundamento de la práctica política: el sabio, el hombre de ciencia, el filósofo, debe tener 
un poder decisivo en el gobierno, debe constituirse en filósofo-gobernante. Y es que, como dice Sabine comentando los textos de La República, "no hay ninguna esperanza para los estados, a menos que el poder se encuentre en manos de quienes saben [...]: el gobierno debe ser un arte basado en un conocimiento exacto" (Sabine, 1963: 42 y 43). Va de suyo que tal planteamiento implica un rechazo de la democracia, en la que — se nos dice- el principal abuso es la ignorancia y la incompetencia de los políticos, que no saben nada como no sea de la adulación del pueblo y de las luchas de partido, y, además, «el pueblo mismo es el gran sofista». Por el contrario, en el modelo platónico, la habilidad profesional del político descansa en el conocimiento científico, esto es, en una educación superior que incluya desde el arte hasta las matemáticas, con el «arte político» como ciencia suprema (y excluyendo las «artes espurias», como la retórica, que es propia de sofistas). Dice Platón, en el conocido párrafo $473 \mathrm{~d}$ de La República que «a menos que los filósofos reinen en las ciudades, o que cuantos ahora se llaman reyes practiquen noble y adecuadamente la filosofía, a menos que vengan a coincidir la filosofía y el poder político, [...] no hay tregua para los males de las ciudades, ni tampoco para los del género humano»3.

Ferrater Mora cree que, para Platón, sólo el «técnico» conoce aquello de que habla. La opinión "común", que toma en cuenta sólo las apariencias, debe ser ignorada. Se nos propone así, para el gobierno de la comunidad, el establecimiento de una suerte de "tecnocracia" (Ferrater dixit) basada en la ciencia, que se opone a la ignorancia de los que no saben (Ferrater, 1982, vol. 3: 2586-2587). Jaeger, por su parte, al comentar Las Leyes, destaca que, para Platón, la causa de la decadencia de un estado es su incultura, su falta de paideia, de modo que una democracia en la que impere la arbitrariedad de la multitud es comparable a una tiranía. En su opinión, la conclusión platónica es que «se debe arrebatar al hombre inculto toda influencia en la dirección del Estado» (Jaeger, 1974: 1041-1043). He aquí, pues, el punto al que conduce la identificación entre virtud y conocimiento, o, dicho de otra forma, la tesis de que la ciencia (esto es, el científico, que es el que sabe) ha de definir los objetivos a que la comunidad haya de aspirar, así como los medios para alcanzarlos. Y García Gual, por último, señala que si los filósofos como Platón atacaron la democracia por considerar inepta a una muchedumbre no ilustrada, otros autores, como Protágoras, señalaron que todo hombre, todo ciudadano, posee capacidad política: en Atenas, «donde cualquier ciudadano podía levantarse y solicitar la palabra en la Asamblea para dar su opinión y pedir una decisión política sobre cualquier tema de carácter general, no se requerían saberes técnicos ni diplomas o títulos especiales para esa intervención» (García Gual, 1990, vol. 1: 91). Qué conocimiento de la realidad social pueda respaldar las opiniones o preferencias manifestadas por los ciudadanos es cosa que habrá de ponerse de manifiesto en el debate a que haya lugar.

3. Utilizo la traducción de José Manuel Pabón y M. Fernández Galiano, Madrid, Centro de Estudios Constitucionales, 3 vols., 1981. La cita se encuentra en el volumen II, p. 158. 
Pero en caso de conflicto entre dicho ciudadano y un científico social partidario de una determinada solución que está, en su opinión, apoyada por la ciencia, no cabe aceptar que se silencie al primero y se atienda sólo a la solución que se pretende científica propuesta por el segundo: esta sería una solución platónica antidemocrática.

\section{La cesura entre ser y deber ser y la normatividad de la ciencia}

Creo necesario reproducir aquí, una vez más, la convicción de Max Weber de que «jamás puede ser tarea de una ciencia empírica proporcionar normas e ideales obligatorios, de los cuales puedan derivarse preceptos para la práctica», y ello por la cesura entre «lo que es» y «lo que debe ser» (Weber, 1973: 41). Lo que Weber está tratando de separar no es sino la ciencia de la política, o, para ser más exactos, intenta evitar que se busquen en la ciencia soluciones a los problemas de la vida buena aristotélica: «una ciencia empírica no puede enseñar a nadie qué debe hacer, sino únicamente qué puede hacer y, en ciertas circunstancias, qué quiere» (Weber, 1973: 44). Si la ciencia estuviera en condiciones de suministrar "preceptos para la práctica», la situación sería la del gobierno de los sabios: dicho en términos actuales, la tecnocracia. Una posición coincidente con la de Weber, formulada desde el campo de la ciencia físiconatural y fundamentada tanto en la especificidad del conocimiento científico, como en su provisionalidad (siempre comprometido con su rectificación en la búsqueda de la verdad), es la de Heisenberg, quien sostiene que:

[...] es imposible fundamentar exclusivamente en el conocimiento científico las opiniones o creencias que determinan la actitud general ante la vida. Tal fundamentación, en efecto, no podría en ningún caso remitir más que al cuerpo de conocimiento científico fijado, y éste no es aplicable más que a sectores acotados de la experiencia. La afirmación que a menudo encabeza los credos de nuestra época, por la que éstos se dan no como materia de mera fe, sino como saber científicamente acreditado, encierra por consiguiente una contradicción interna y se basa en una ilusión. (Heisenberg, 1993: 23-24)

Pero en la vecindad de dicha cuestión hay otro problema diferente: el de que sea o no posible la ciencia social, a la vista de la inevitable presencia de valores que colorean el trabajo del científico. Weber sabe que los valores personales se introducen siempre en la investigación, lo que sin duda cuestiona la objetividad. El problema es que ni es posible una suerte de neutralidad o indiferencia moral (no puedo desnudarme de mis valores como si me quitara la ropa), ni es éticamente exigible. La objetividad de la ciencia no puede descansar en el indiferentismo moral, ya que, frente al mal, a la opresión, a la discriminación y a la explotación no se puede ser indiferente. La solución está, cabe adelantarlo con el imprescindible escepticismo, en que las coloraciones ideológicas no impiden la investigación científica ni excluyen su solvencia, pero exigen una actitud crítica permanente, tanto en el propio investigador como en la comunidad científica de la que forma parte. 
¿Cómo distinguir los argumentos empíricos (relativos al ser) de los evaluativos (propios del deber ser) a la hora de enfrentarse con los problemas sociales? La gente fija los fines sociales y los medios para lograrlos a través de procesos sociales, como los que tienen lugar de manera institucional en una democracia, aunque claro está que hay otras formas de fijarlos, como sucede con una oligarquía, una clase dominante o un tirano. Pero esa gente que establece los fines sociales no lo hace de manera unánime, sino dividida y enfrentada en una lucha. La democracia institucionaliza el conflicto y establece las reglas a que ha de ajustarse. ¿Qué tiene todo ello que ver con la producción de conocimiento científico sobre la realidad social? Algo, sin duda: las ideologías y los intereses están también presentes en la investigación científica, el desacuerdo entre científicos es normal, y la ciencia social está presente en la política, al menos como principio de realidad; además, la lógica de los fines sociales se trae al ámbito de la ciencia para su discusión racional, pero sólo para eso. Porque no se concluye que una u otra medida haya de aplicarse de manera indiscutible.

Hay, por tanto, dos cuestiones distintas en el tema de la relación entre las convicciones políticas y sociales y la ciencia social: en primer lugar, la necesidad de que la ciencia se abstenga de formular propuestas de acción respaldadas con la autoridad que su origen les otorgaría, y ello porque la ciencia no puede saltar del plano del conocimiento (del ser) al de la acción política (del deber ser), porque uno y otro carecen de conexión lógica o moral, no puede pasarse de uno a otro. La tecnocracia consiste precisamente en que, con el pretexto del respaldo indiscutible que otorgaría el conocimiento científico, se usurpa la voz del ciudadano, el único que puede optar por la fórmula de vida buena que sus convicciones le pidan. Pero, en segundo lugar, y en una relación aparentemente contradictoria con la anterior, está la imposibilidad de que el científico social ignore sus valores mientras se dedica a las actividades propias de la ciencia, recuperándolos en el resto de su tiempo, o la de que intente una suerte de neutralización de sus convicciones, una indiferencia moral en la que pueda mirar a la realidad social sin que su mirada se vea coloreada por el rechazo de (lo que él piensa que es) la injusticia. Siendo esto así, ¿̇cómo es posible una ciencia social objetiva, no distorsionada por las convicciones del científico social? No se trata aquí, pues, de que se revistan del prestigio de la ciencia determinadas líneas de acción social o política, con lo cual se convertiría el modo de gobierno en una tecnocracia, sino de algo mucho más básico: la cuestión de la posibilidad de una ciencia social que se produce inevitablemente contaminada con los valores morales, sociales y políticos del científico (y que Weber cree ingenuamente resolver con un ejercicio de explicitación de dichos valores ${ }^{4}$ ).

En resumidas cuentas, de una parte, hay que insistir en que, desde la ciencia social, no pueden formularse propuestas dotadas de la autoridad de la ciencia para resolver los problemas de la vida social (lo que no obsta, claro está, a que

4. Véase, al respecto, en mi libro Ciencia y Sociología (Madrid, Centro de Investigaciones Sociológicas, 3a ed., 2001), una discusión del tema en las páginas 20 a 23, cuando Weber asumió la codirección del Archiv für Sozialwissenschaft und Sozialpolitik. 
quienes han de resolverlos acudan a la ciencia social como principio de realidad5 para hacer viables sus planteamientos y soluciones). Y, de otra, es preciso señalar que toda la ciencia social está hecha desde una mirada a la realidad coloreada por los valores del investigador, valores de los que no sería ético prescindir (ya que no se puede ser neutral ante el mal), ni sería posible prescindir; pese a lo cual seguimos hablando de ciencia social, que es, en efecto, ciencia pese a todo (gracias a determinadas salvaguardas y reservas). Uno debe comprometerse con sus propios valores, comprometiéndose al mismo tiempo con los hechos de la realidad. Hay que diferenciar ambos planos y no confundirlos. No se puede pontificar sobre las concepciones del mundo en nombre de la ciencia, amparándose en la presunta objetividad de ésta.

Sin embargo, como he recordado más arriba, para algunos el propósito de la sociología es lograr una sociedad más justa. Se piensa que ello tiene que ver con la compasión, con la mejora del nivel de vida de los más pobres o con la desaparición de la explotación. Es obvio que el conocimiento de la realidad social aportado por la sociología puede ayudar a realizar esos fines humanitarios, pero no es ese su primer objetivo, sino el de lograr un conocimiento más completo y fiable de las estructuras y de los procesos sociales. El conocimiento de la realidad social obtenido gracias a la sociología no permite saber cómo deberían ser las cosas, y menos aún sostenerlo con la autoridad de la ciencia. Decir en qué ha de consistir la vida buena (por emplear la expresión de Aristóteles) no ha de corresponder al "experto», a ningún experto, so pena de caer en la tecnocracia, sino al ciudadano, a cualquier ciudadano libre de expresar sus ideas. Así pues, no es propósito de la sociología cambiar el mundo (ni, por el contrario, legitimar el orden social existente), sino saber más sobre la realidad social, lo que, como se indicó más arriba, es en último extremo emancipador, pues contribuye a liberarnos de la ignorancia y de los idola (usando de nuevo el término de Bacon), tanto por poner de manifiesto la realidad objetiva, como por deconstruir la realidad socialmente construida y desenmascarar lo que hay debajo de ella. Lleva razón Hacking cuando dice que «el objeto fundamental del desenmascaramiento es liberar al oprimido», y añade que "en última instancia, la objetividad ha sido el último apoyo de los débiles» (Hacking, 2001: 103 y 161). Por mi parte, no veo ninguna contradicción entre el empeño en la objetividad y la convicción de que parte al menos de la realidad social ha sido socialmente construida: ésta va un paso más allá que aquél al bucear en el origen social de las apariencias que encubren o disimulan la desigualdad o la explotación, al deconstruir la parte de la realidad construida.

Pues bien, cuando se sostiene, como aquí se hace, que el propósito primordial de la sociología es el conocimiento de la realidad social, no su transforma-

5. Tomo la expresión, como es notorio, de Freud, aunque no en su sentido estricto, que la enfrenta al «principio del placer». Cf. su Compendio del psicoanálisis, capítulo VIII, tomo IX de las «Obras Completas», Madrid, Biblioteca Nueva, 1975, p. 3413. He insistido varias veces en que tal principio de realidad implica la necesidad de que la actuación de las administraciones públicas esté permanentemente conectada con la situación de hecho sobre la que han de incidir. 
ción, la experiencia me dice que ello provoca el rechazo de los más generosos: la «curiosidad intelectual» resulta una motivación frívola frente al «compromiso». Y tanto más a la vista de que el conocimiento científico es indispensable para la eficacia de las propuestas de cambio político y social, hasta el punto de confundirse muchas veces con ellas. Entiendo que dichas propuestas no son cosa de los científicos sociales qua científicos, aunque sí, desde luego, en tanto que ciudadanos. Lo que el científico social no puede hacer es asumir el papel del político, es decir, disponer qué es lo que ha de hacerse porque él es quien sabe, quien tiene el conocimiento. El conocimiento de la realidad social no autoriza a establecer los fines sociales, aunque, como principio de realidad, haya de acompañar a dicho establecimiento y contribuir a determinar los medios para lograrlos.

\section{Para un tratamiento crítico-racional de los fines sociales ${ }^{6}$}

Pero, al menos en un aspecto, la sociología puede y debe acceder de manera normativa a esa dimensión de la realidad social en la que se establecen y se discuten los fines para la vida buena, careciendo de toda pretensión de decirle a la gente qué es lo que le conviene y limitándose a «señalar criterios de racionalidad conforme a los que enjuiciar el ethos de las formas de vida existentes» (Habermas, 1991: 82). Las ciencias sociales, y en particular la sociología, tienen como parte de su objeto de conocimiento la consideración de los fines sociales, cuya discusión racional les es propia, con lo cual se niega que éstos hayan de ser relegados a una discusión meramente ideológica. Entiendo que se trata de lo que Max Weber había llamado "crítica técnica» de los valores, que no tienen por qué quedar excluidos de su consideración por las ciencias sociales, al menos en lo que se podría considerar su condición de valores "siendo", no de valores «valiendo» (Beltrán, 2001: 16-18).

En 1937, señalaba Horkheimer, en un famoso artículo, que «las varias escuelas de sociología tienen idéntica concepción de la teoría, y ésta es la de las ciencias naturales [...]. En esta concepción de la teoría, la función social realmente cumplida por la ciencia no se hace manifiesta; no se explica lo que la teoría significa para la vida humana» (Horkheimer, 1976: 209 y 212). Tal manera de ver las cosas, rechazada por el autor, parte de que los científicos se dedican a actividades meramente clasificatorias y consideran la realidad social como extrínseca, enfrentándose a ella como científicos y no como ciudadanos. Consecuentemente, la realidad se concibe como una serie de datos que han de ser manejados, sin mayor implicación de la actividad científica en la organización racional de la actividad humana para la construcción de un mundo que satisfaga las necesidades de los hombres. Frente a esta tradición positivista de la ciencia, Horkheimer opone la teoría crítica, que «nunca busca simplemente un incremento del conocimiento como tal: su objetivo es la emancipación del

6. Trato el tema con algo más de detenimiento en mi libro La realidad social, 2a ed., Madrid, Tecnos, 2003, p. 128 y s. 
hombre de la esclavitud» (Horkheimer, 1976: 224). El mismo autor sostuvo, en 1947, que el positivismo científico implica consagrar la que llama «razón subjetiva o instrumental» y rechazar la razón objetiva: se considera que la tarea de la razón "consiste en hallar medios para lograr los objetivos propuestos en cada caso" (Horkheimer, 1973: 7), sin reparar en qué consiste en cada caso el objetivo específico propuesto. La razón tiene, así, que habérselas tan sólo «con la adecuación de modos de procedimiento a fines que son más o menos aceptados y que presuntamente se sobreentienden» (Horkheimer, 1973: 15). Los fines no son, pues, manejables por la razón instrumental, esto es, por la ciencia positivista. Constituyen algo dado, sobreentendido. La ciencia se ocupa de clasificar y deducir, de adecuar medios a fines. En contraste con ello, para Horkheimer, la ciencia articulada como razón objetiva debe enfocarse sobre «la idea del bien supremo, del problema del designio humano y de cómo realizar las metas supremas» (Horkheimer, 1973: 17). De no ser así, resultaría que «no existe ninguna meta racional en sí, y no tiene sentido entonces discutir la superioridad de una meta frente a otras con referencia a la razón» (Horkheimer, 1973: 17-18). Cuando el positivismo relega los fines humanos a las tinieblas exteriores (esto es, cuando niega que la ciencia pueda ocuparse de valores valiendo), limita la razón al papel puramente instrumental de enjuiciar la adecuación de medios diversos a fines dados: lo que el positivismo consagra es la no racionalidad de la esfera de los fines, y lo que la teoría crítica reivindica es justamente la restitución de los fines del hombre al ámbito de la racionalidad, esto es, de la ciencia. Pero, con ello, la teoría crítica no trata de sustituir la política por la ciencia, sino que la ciencia recobre su competencia para la consideración racional de los fines del hombre, lo que implica reclamar para la ciencia el ejercicio de la reflexión racional, y no sólo la práctica del empirismo positivista que se niega a ir más allá de los hechos. Esto es lo que significa en último extremo la expresión «teoría crítica», frente a la "celebración de la sociedad tal como es», en la conocida frase de Mills.

Pues bien, este reclamar para la ciencia social el ejercicio de la racionalidad en la consideración de los fines, en este caso de los fines sociales, es tanto como decir que uno de los métodos de la sociología ha de ser el crítico-racional. Se trata, como a la vista está, de discutir y apreciar la racionalidad de los fines, cuestión de la que la ciencia positivista no quiere saber nada, ya que es una cuestión de valores, por lo que se limita a la de la racionalidad de los medios en términos de su adecuación a fines dados, es decir, a una racionalidad instrumental planteada como cuestión meramente técnica.

Debe quedar claro que la consideración de la racionalidad de los fines no implica ningún contenido dogmático, en el sentido — vulgar si se quiere — de que la ciencia social hubiera de suplantar la decisión política, con lo cual se llega a la engañosa utopía del gobierno de los sabios. Por el contrario, de lo que se trata es del ejercicio racional de la crítica de fines, de la negación a lo existente de su postulada condición de orden natural necesario, de mostrar el pedestal de barro en que descansan los idola de todo tipo. La consideración de la racionalidad de los fines sociales no tiene por objeto absolutizar ningu- 
no de ellos, sino más bien corromper la fe en el pretendido carácter absoluto de alguno de ellos. Y me apresuro a decir que no se trata de que a la ciencia social pueda darle igual un fin que otro. La justicia siempre será mejor que la injusticia o la libertad mejor que la opresión, y la ciencia social deberá señalar la injusticia implícita en posiciones que se pretenden justas, o los recortes a la libertad que se presenten como conquistas de la libertad. No hay, pues, vestigio alguno de relativismo axiológico en la constatación de que el papel normativo de la ciencia social es más bien de crítica que de propuesta, y que, en el caso de esta última, tratará de defender valores y no programas políticos concretos. No se trata, pues, de arropar con el eventual prestigio de la ciencia opciones políticas que se presentarían públicamente como indiscutibles, sino de someter a discusión racional los fines propuestos y sus alternativas. Y no cabrá normalmente esperar una posición unánime de la comunidad científica en cada punto sujeto a discusión, del mismo modo que no existe tal unanimidad ni siquiera en el pretendido ámbito neutral exento de valoraciones en que la ciencia social positivista afirma moverse. $Y$ creo que es necesario estar de acuerdo con Isaiah Berlin cuando sostiene que "no hay duda de que el intento consciente de aplicar los métodos científicos a la regulación de los asuntos humanos hizo un gran bien: el sufrimiento fue mitigado, se evitó o previó la injusticia y se desenmascaró la ignorancia. [...]. Pero el sueño principal, la demostración de que [...] todos los males podían ser curados si se seguían los pasos tecnológicos adecuados, [...] resultó ser ilusorio» (Berlin, 2000: 93).

Creo que no tendría sentido discutir acerca de que la objetividad sea condición básica del conocimiento científico, pues objetividad implica referir éste a lo que sea propio del objeto y no a nuestros deseos, sentimientos o imaginación. La subjetividad en la descripción del objeto implica una arbitrariedad que hace imposible la confianza en los resultados de la observación, que es un requisito esencial para la ciencia. Afirmar la necesidad de la objetividad de la práctica científica que conduce al conocimiento supone, pues, esperar una actitud impersonal del científico social, esto es, una actitud de imparcialidad ideológica, de neutralidad moral, como predisposición para la investigación y el conocimiento. Pero la cuestión, como se ha apuntado más arriba, es que hay que tomar partido, que no se puede ser neutral frente a la injusticia o la opresión. Y, llegados a este punto, se plantea no sólo un problema epistemológico en relación con la objetividad (¿cómo afectarán mis legítimas convicciones a la mirada que dirijo al objeto?), sino un problema político en relación con mi compromiso con los valores que para mí son universales, pues lo que yo entienda por «justicia» o por «libertad» puede no ser entendido así por otros, por personas que comparten valores diferentes a los míos. Se trata, pues, de una aporía que nos devuelve a lo más básico de la discusión sobre hechos y valores. Por un lado, la neutralidad moral no es admisible como exigencia de la práctica de la investigación científica, ya que no cabe como postura ética; pero, por otro lado, mi sentido de la justicia, por ejemplo, no será compartido por todos, e incluso habrá quien valore como injusta la situación que para mí encarna la justicia. Mi interlocutor y yo podemos estar de acuerdo en reco- 
nocer la realidad de un determinado hecho y disentir en su valoración: pero es posible que nuestra discrepancia valorativa vaya más lejos y contamine la misma realidad del fenómeno, de manera que el hecho será visto por uno y por otro de manera diferente.

Señala Lindblom (1990: 4 y 5) que un problema social lo es sólo cuando la gente define una situación como necesitada de mejora. Pero lo que para unos constituye un problema no lo es para otros, e incluso qué sea una solución o una mejora es algo que varía de persona a persona. La cuestión, por tanto, se convierte en un proceso de resolución de conflictos entre grupos sociales, cada uno de los cuales define el problema de una manera y prefiere una determinada solución, lo que al final termina implicando algún tipo de debate que aporte argumentos que permitan modificar las posiciones enfrentadas, de forma que se haga posible una solución que no venga impuesta por la fuerza. Tales argumentos pueden ser racionales y lógicos, o al menos tratarán de parecerlo, incluso apoyándose en un conocimiento de la realidad que permita un salto pretendidamente justificado al deber ser. En todo caso, y si no se produce acuerdo, se dará la prevalencia de un grupo sobre otro. El desacuerdo no es sólo ideológico, sino que, con frecuencia, lo que hay es una incompatibilidad de intereses en juegos de suma cero. Todo descansa, pues, como en un eco de Isaiah Berlin, en que ni los problemas sociales son los mismos para todos, ni son siempre solucionables, ni sus eventualmente posibles soluciones son compatibles entre sí.

\section{La reflexividad transformadora}

En todo caso, el conocimiento de la realidad social que la sociología va logrando, sea verdadero o falso, al hacerse público, produce sin duda consecuencias sobre dicha realidad social, no sólo porque en ciertos casos pueda desenmascarar determinados factores perjudiciales que permanecían ocultos, sino porque, en general, hay un inevitable proceso de reflexividad entre la sociedad y el conocimiento que adquiere de sí misma a través de las ciencias sociales. Quiero decir que las descripciones y explicaciones de la realidad social que formulen públicamente las ciencias sociales alterarán la realidad explicada o descrita. Esta reflexividad ya fue percibida por Murillo en 1958, al señalar que la realidad social es especialmente sensible a la influencia de las ideas formuladas sobre dicha realidad, lo que le empujaba a «plantear el problema del futuro de una sociedad que [...] está sometida desde hace más de un siglo a estudios científicos llevados a cabo de un modo sistemático». Y es que «si la realidad estudiada por las ciencias de la naturaleza es insensible a lo que los hombres piensan de ella, no sucede lo mismo con la realidad que estudia la Sociología» (Murillo, 1987: 187). El autor deja claro que no se está refiriendo a la utilización de los conocimientos de las ciencias sociales como técnicas para manipular la sociedad, sino al condicionamiento de la realidad por el saber sociológico, esto es, a una suerte de Wissenssoziologie al revés. De la cuestión se ha ocupado también Lamo de Espinosa, quien la ha expresado con la metáfora del científico social 
constituido en espejo a través del que la sociedad reflejada reflexiona sobre sí misma. Reflexividad transparente la llama, en la medida en que trata de eliminar toda opacidad (Lamo, 1988: 47).

En resumidas cuentas, a la hora de examinar el papel de las ciencias sociales, y en particular de la sociología, respecto de los fines sociales e incluso de las cadenas instrumentales formadas por medios y fines, salta a la vista que hay que distinguir dos ámbitos muy diferentes: la sociología académica, cuya investigación se centra en el conocimiento de una realidad extremadamente compleja, y la discusión pública en los medios de comunicación y en la vida cotidiana de lo que a ellos llegue de los resultados de dicha investigación, esto es, del conocimiento de la realidad social. Es verdad que buena parte de eso que llega se ha elaborado precisamente para el consumo público (y el caso más claro es el de los estudios de opinión, habitualmente bajo la forma de encuestas llevadas a cabo por empresas especializadas contratadas por los propios medios), con lo que la sociedad, colocada frente al espejo en que se ve reflejada, reacciona reflexivamente a lo que se dice de ella. Y para que el fenómeno se produzca, sólo se requiere que tal conocimiento se haga público.

Se trata, pues, de algo muy diferente de la pretensión de normatividad de las ciencias sociales predicada incondicionalmente por algunos de sus practicantes, que implicaría una deliberada propuesta de acción, supuestamente basada en el conocimiento científico de la realidad social. No cabría, pues, la discusión, no sería posible disentir acerca del objeto de la propuesta ni de los medios para llevarla a cabo, pues no es imaginable que los no expertos discutan a quienes sí que lo son, con lo que los ciudadanos quedarían expropiados de la responsabilidad de establecer los fines de la vida colectiva de acuerdo con sus convicciones y a través de los mecanismos que el régimen democrático establece. Un teórico de la economía sostiene que ésta, en muchas cosas, tiene muy poco que decir: «cada sociedad toma decisiones sobre el grado y la forma de intervención del Estado. Esta es una facultad que compete al ciudadano y que el ciudadano tiene, además, obligación de ejercer» (Pastor, 2007: 276-277): la política no puede ser sustituida por la ciencia como criterio para el establecimiento de los objetivos y de las políticas sociales, pero la ciencia, en la medida en que sus hallazgos se hacen públicos, produce efectos sobre una realidad a la que termina afectando desde el espejo que la refleja.

\section{Asesoría a los centros de decisión ${ }^{7}$}

La pregunta sobre el papel de los valores en la investigación social ha de ser completada con el que tienen en la asesoría científica a los centros de decisión. ¿Puede la ciencia social proporcionar respuestas a consultas para la adopción de decisiones políticas?, ¿cómo colabora el científico en la acción inspirada por

7. Se ocupó de la cuestión Rafael López Pintor, en «El papel de los valores en la investigación social y la asesoría a los centros de decisión", Revista Española de la Opinión Pública, 34, octubre-diciembre de 1973. 
determinados valores? Dejando aparte en este momento la posición marxiana de una ciencia comprometida políticamente, para la que no existe el problema, "Weber acepta la idea de colaboración entre ciencia y política y la incorpora existencialmente a su propia vida», aunque con claras limitaciones: «aparte de aconsejar sobre los medios para alcanzar un fin específico o sobre el sentido de ese fin dentro de un contexto determinado, el científico debe mantener silencio» (López Pintor, 1973: 112). Pero dejemos que sea el propio Weber quien señale esas limitaciones:

Cualquier reflexión conceptual acerca de los elementos últimos de la acción humana provista de sentido se liga, ante todo, a las categorías de «fin» y «medio». Queremos algo en concreto «en virtud de su valor propio» o como medio al servicio de aquello a lo cual se aspira en definitiva. A la consideración científica es asequible ante todo, incondicionalmente, la cuestión de si los medios son apropiados para los fines dados. En cuanto podemos (dentro de los límites de nuestro saber en cada caso) establecer válidamente cuáles medios son apropiados o ineptos para un fin propuesto, podemos también, siguiendo ese camino, ponderar las oportunidades de alcanzar un fin determinado en general con determinados medios disponibles, y, a partir de ello, criticar indirectamente la propuesta de los fines mismos, sobre la base de la situación histórica correspondiente [...] Podemos también, si la posibilidad de alcanzar un fin propuesto aparece como dada, comprobar las consecuencias que tendría la aplicación del medio requerido, además del eventual logro del fin que se busca, a causa de la interdependencia de todo acaecer. Ofrecemos de este modo a los actores la posibilidad de ponderar estas consecuencias no queridas con las buscadas, y con ello de responder a la pregunta: :Cuánto «cuesta» el logro del fin deseado en los términos de la pérdida previsible respecto de otros valores? (Weber, 1973: 42)

En mi opinión, es a este tipo de trabajo científico sobre los valores a lo que Weber llama crítica técnica, orientada al dictamen acerca de la adecuación de medios a fines, de la producción de consecuencias queridas o no y del costo de determinados fines o valores en términos de pérdidas de otros fines o valores. Creo que Weber trata aquí de los términos en que, a su juicio, es posible la asesoría científica a los centros de decisión política, limitada a ponderar medios, consecuencias y costos respecto de fines dados o propuestos. Y continúa: «Ahora bien, extraer una decisión de aquella ponderación no constituye ya una tarea posible para la ciencia» (Weber, 1973: 42). Se opone, pues, a que la asesoría vaya más allá y desemboque en decisiones prácticas, con lo que «hacer sociología puede ser una manera desviada de hacer [...] política». En la medida en que el experto propone aplicar los conocimientos científicos a la adopción de decisiones políticas, se coloca de hecho en una posición inapelable y convierte su dictamen en indiscutible por venir amparado por la ciencia. Como dice Claude Grignon: «cuanto más neutra o imparcial es o parece ser la experticia, tanto mejor justifica las decisiones políticas: al reducirlas a imperativos técnicos, les da un fundamento racional [...]: lo político se cobija tras el experto» (Grignon, 2006: 150). 
En resumen, la asesoría que un sociólogo puede prestar a los centros de decisión política cubre los siguientes extremos: ante todo, decir cómo es la realidad y, en caso de saberse, por qué es así. En otras palabras, poner a disposición de quien ha de tomar la decisión el conocimiento descriptivo, y eventualmente explicativo, de la realidad social. No es una pequeña aportación: se trata, nada menos, que de ofrecer el resultado de la investigación científica al respecto, para que no sea ampliamente ignorado, o contemplado con escepticismo por su frecuente choque con el sentido común o por contradecir las apariencias. Está claro que tal aportación no resuelve, por sí misma, el problema de la decisión, e incluso con frecuencia lo complica, pero tener como punto de partida una información fiable de cómo son las cosas es, sin duda, un importante factor de racionalidad en la decisión que termine adoptándose.

Un segundo plano de la asesoría puede referirse al fin o al objetivo que pretende eventualmente formular el órgano decisor, que es sometido a la consideración del experto, bien para que considere su racionalidad (y sin que una conclusión positiva implique que la ciencia lo aprueba por boca del experto), o su viabilidad, tanto en el sentido de que pueda ser factible el propósito de alcanzarlo, como en el de que sus costos sean asumibles, incluso en términos de lo que haya de perderse en otros valores o fines que puedan ser negativamente afectados.

En tercer lugar, la asesoría puede versar sobre la adecuación de medios a fines dados, ya decididos o en proceso de selección (pendientes incluso de que el asesor pueda señalar los medios adecuados para el fin propuesto). La asesoría habrá de señalar, en su caso, posibles medios alternativos, toda vez que, con frecuencia, las opciones importantes recaen precisamente sobre los medios, que pueden provocar conflictos en función de su utilización alternativa. Sin duda, y en caso de ser posible, la asesoría debe extenderse a los eventuales efectos perversos de las medidas (medios y fines) que puedan ser decididas. El experto puede predecir efectos que podrían no estar previstos y que hay que tener en cuenta o efectos no queridos, pero que quizás sea necesario arrostrar en los planes de acción del órgano decisor. Por último, una vez adoptada y puesta en práctica la decisión, el experto asesor podrá ocuparse a posteriori de comprobar la eficacia de la actuación de que se trate y ver en qué medida ha producido los efectos deseados, así como constatar la eficiencia con que la operación se ha llevado a cabo para evitar la dilapidación o el mal empleo de los recursos públicos.

Así pues, en tanto que científico social, el experto no decide, puesto que ello corresponde a los ciudadanos y a sus representantes políticos, y no a la ciencia, pero como asesor acompaña al decisor en todo el proceso: le señala la realidad que hay que tener en cuenta y de la que hay que partir, considera la racionalidad y la viabilidad de los fines que maneja el decisor y de los medios que mejor se les adecúan, advierte de los posibles efectos perversos de la decisión que se esté preparando y evalúa los resultados de la acción llevada a cabo, tanto su eficacia como su eficiencia, e incluso la acogida de la misma por la opinión pública. La asesoría a los centros de decisión es, pues, algo que 
compete a las ciencias sociales, pero el científico siempre debe dejar claro que las decisiones que se adopten con su asesoramiento no vienen impuestas por la autoridad de la ciencia, sino que han de ser el resultado del ejercicio de un derecho y la asunción de una responsabilidad por parte de los ciudadanos y sus representantes políticos.

Los titulares del poder político, que actúan a partir de su ideología y de los intereses de los grupos sociales a los que pertenecen o representan, intentan no actuar a ciegas; por ello se asesoran por personas "que saben", tanto por sociólogos (que es el supuesto que hemos considerado), como por expertos que no son científicos sociales. Todas las organizaciones administrativas están servidas por funcionarios profesionales, y la formación de algunos de ellos implica capacitación técnica y conocimiento en el ámbito de las ciencias sociales. A partir de esa capacitación, son llamados a asesorar en la implementación de la acción pública como tales expertos, no por su ideología, y sin que ello implique necesariamente una situación de Beamtenherrschaft, como las que tanto peocupaban a Weber. Por consiguiente, en un régimen democrático moderno, hay, pues, una considerable dosis de poder del conocimiento, de tecnocracia si se quiere, aunque no proceda, en la mayor parte de los casos, de científicos sociales, tanto para identificar problemas sociales como para echar mano de lo que se sabe de la realidad, tanto para establecer fines como para señalar los medios adecuados para lograrlos. Y todo ello como resultado de la penetración del conocimiento en todos los ámbitos de la vida, desplazando (u ocultando) ideologías e intereses, aunque no pueda afirmarse en modo alguno que la sociedad del conocimiento haya eliminado a la política.

\section{Para concluir}

El rol del científico social qua científico consiste en incrementar y mejorar el conocimiento de la realidad social, y por el hecho de hacerlo está ya llevando a cabo una labor emancipadora al negar el discurso de los idola y al deconstruir la realidad socialmente construida. Pero, al asesorar a los centros políticos de decisión en favor de objetivos humanitarios, puede y debe ir más allá, puesto que con ello contribuirá a aumentar la racionalidad y la moralidad de la decisión con la aportación del principio de realidad y con la crítica técnica de los valores. Pero, en su tarea como asesor, no puede asumir mayores responsabilidades, a menos que decida cambiar de rol, abandonando el de científico y tomando el de político. Ahora bien, si lo hace, deberá dejar claro que las decisiones que adopte en su nuevo rol no se fundan en la autoridad de la ciencia, sino que decide en su condición de homo volens y, por tanto, en un terreno discutible en el que es legítimo y racional que existan otras opciones.

Sin embargo, las cosas son, desde el principio, complicadas. La descripción y la explicación de la realidad social no puede ser sino el resultado de la investigación científica objetiva, no de una construcción retórica, arbitraria o panfletaria. Pero si no se puede proponer la neutralidad ética como condición de dicha investigación, y es obvio que no se puede, hay ya ahí una fuente de 
dificultades para la ciencia. No acaban ahí las cosas: la propia delimitación del objeto de conocimiento se lleva a cabo, si hemos de creer a Weber, a través de la selección que los valores del investigador operan en el caos de la realidad social, señalando lo que, de acuerdo con ellos, es relevante o destacable. El uso metodológico de los valores del investigador para señalar el objeto de conocimiento implica que otros investigadores, identificados con valores diferentes, seleccionarán aspectos distintos de la realidad, objetos de conocimiento diferentes, y no es lo mismo ver en la realidad unas cosas u otras, aunque a todas se las trate con exquisita objetividad. Ciertamente, unas y otras serán fragmentos objetivos de la realidad investigada, pero es obvio que no darán igual, sobre todo si la visión del todo al que se remite el sentido de los fragmentos es también diferente para unos y para otros investigadores. Pues bien, sostener que, pese a todo, son posibles las ciencias sociales, y en concreto la sociología, exige dar un paso más y reclamar, para el investigador y para la comunidad científica de la que forma parte, una actitud autocrítica y una práctica crítica sistemática que permitan señalar los límites de la objetividad, establecidos por los inevitables valores del investigador y por el previsible conflicto de valores.

He aquí, pues, en resumen, que, habiendo empezado por plantear la disyuntiva de la vocación de la ciencia por el conocimiento de la realidad o por la transformación social, hemos terminado discutiendo una vez más si es posible la ciencia social, a la vista de que los valores del investigador hacen problemática su objetividad. En ambos casos, el riesgo para la ciencia es grande: en uno, convertirse en tecnocracia al formular programas de acción que se presenten como indiscutibles por ser "científicos»; en el otro, ofrecer una visión sesgada de la realidad, deformada por los valores del investigador. Tanto en un caso como en el otro, el contexto implica un conflicto: de alternativas posibles en el ámbito de los fines sociales (o incluso de los medios utilizables para alcanzar un fin que no se discuta), o de valores diferentes, y hasta contrarios, a la hora de percibir la realidad a través de ellos. Pero, inextricablemente mezclados con esa cuestión, están dos grandes temas de la sociología: el de la construcción social de la realidad y el de la sociología del conocimiento. Pues bien, el sociólogo aceptaría que el pensamiento crea (construye) (cierta) realidad (social), y que la realidad (social) crea (o al menos influye, condiciona y a veces determina) (cierto) pensamiento. Es verdad que, en la frase anterior, abuso de los paréntesis que recortan, matizan o limitan lo que sin ellos se diría abruptamente: que realidad y pensamiento juegan entre sí, generándose mutuamente. El pensamiento genera realidad, tanto por medio de su construcción social, como a través del fenómeno de la reflexividad, y la realidad social genera pensamiento en la medida en que éste no se produce en el vacío, sino en el seno de la estructura social.

Pero eadem sed aliter. Diciendo lo mismo de otra manera, lo cierto es que entre la posición marxista de que se trata de transformar el mundo en lugar de limitarse a interpretarlo, y la doctrina positivista de que el propósito de las ciencias sociales se limita a la episteme o conocimiento de la realidad, vemos 
que existe un campo extraordinariamente amplio en el que se entrecruzan ciencia y valores, conocimiento y política, neutralidad y normatividad. Vivimos en la sociedad del conocimiento, en la que la reflexividad es un fenómeno constante, en la que no deben dejarse los fines sociales fuera del ámbito de la discusión racional y en la que científicos y funcionarios expertos asesoran a los políticos gracias al conocimiento de la realidad que las ciencias sociales ponen a su disposición. Y, en todo caso, las ciencias sociales son emancipatorias por el solo hecho de llamar a la realidad por su nombre. Todo ello, claro está, en un contexto en el que la identificación de algo como un "problema social» puede no coincidir con la del vecino, $y$, aunque ambos coincidan, es fácil que discrepen en cómo haya de resolverse y qué medios sean los apropiados para ello. Por eso decía, al principio de estas páginas, que me parece que el problema carece de una solución clara y satisfactoria.

\section{Referencias bibliográficas}

ARistóteles (1949). Ética a Nicómaco. Madrid: Instituto de Estudios Políticos. Traducción de M. Araujo y J. Marías.

BeCK, U.; Giddens, A. y LASH, S. (1997). Modernización reflexiva: Politica, tradición y estética en el orden social moderno. Madrid: Alianza.

Beltrán, Miguel (2001). Ciencia y Sociología. 3a ed. Madrid: Centro de Investigaciones Sociológicas.

- (2003). La realidad social. 2a ed. Madrid: Tecnos.

- (2005). «Sobre la necesidad de acudir a los autores clásicos de la sociología». En: ARIÑO, Antonio (ed.). Las encrucijadas de la diversidad cultural. Madrid: CIS.

- (2007). «Anotaciones a tres textos de Carlos Moya». En: VVAA. Lo que hacen los sociólogos: Libro homenaje a Carlos Moya Valgañón. Madrid: Centro de Investigaciones Sociológicas.

BeLL, Daniel (1960). The End of Ideology. Illinois: The Free Press of Glencoe.

BERLIN, Isaiah (2000). «Los filósofos de la Ilustración». En: El poder de las ideas. Madrid: Espasa.

Ferrater Mora, José (1982). Diccionario de Filosofía. 4 vols. Madrid: Alianza.

Freud, Sigmund (1975). Compendio del psicoanálisis. Obras Completas, tomo IX. Madrid: Biblioteca Nueva.

García Gual, Carlos (1990). «La Grecia antigua». En: Vallespín, Fernando (ed.). Historia de la teoría política, vol. I. Madrid: Alianza.

GrignON, Claude (2006). «Sociología, experticia y crítica social». En: LAHIRE, Bernard (ed.). ¿Para qué sirve la sociología? Buenos Aires: Siglo XXI.

HabERMAS, Jürgen (1991). Escritos sobre moralidad y eticidad. Barcelona: Paidós.

HACKING, Ian (2001). ¿La construcción social de qué? Barcelona: Paidós.

HeISENBERG, Werner (1993). La imagen de la Naturaleza en la fisica actual. Barcelona: Planeta-Agostini.

HorkHeIMER, Max (1973). Crítica de la razón instrumental. Buenos Aires: Sur (edición original de 1947).

- (1976). «Traditional and Critical Theory». En: ConnerTon, Paul (ed.). Critical Sociology. Harmondsworth: Penguin.

Jaeger, Werner (1974). Paideia: los ideales de la cultura griega. México: Fondo de Cultura Económica. 
LAMO DE EsPINOSA, Emilio (1988). «Predicción, reflexividad y transparencia: La ciencia social como autoanálisis colectivo». Revista Española de Investigaciones Sociológicas, 43, julio-septiembre.

LindBLOM, Charles E. (1990). Inquiry and Change. New Haven: Yale University Press.

LÓPEZ PINTOR, Rafael (1973). «El papel de los valores en la investigación social y la asesoría a los centros de decisión». Revista Española de la Opinión Pública, 34, octubre-diciembre.

Murillo, Francisco (1987). «Sociología del saber sociológico: El impacto sociológico en la sociedad». En: Ensayos sobre sociedad y politica, vol. I. Barcelona: Península (edición original del artículo de 1958).

PASTOR, Alfredo (2007). La ciencia humilde: Economía para ciudadanos. Barcelona: Crítica.

Platón (1981). La República. Madrid: Centro de Estudios Constitucionales. 3 vols. Traducción de José Manuel Pabón y M. Fernández Galiano.

Sabine, George H. (1963). Historia de la Teoría Política. México: Fondo de Cultura Económica.

WeBER, Max (1973). «La "objetividad” cognoscitiva de la ciencia social y de la política social». En: Ensayos sobre metodología sociológica. Buenos Aires: Amorrortu. 